(2)

\title{
New developments in the treatment of chronic lymphocytic leukemia: role of obinutuzumab
}

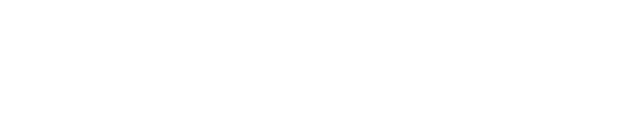

\author{
Arpita Shah \\ Department of Pharmacy, Georgia \\ Regents University Medical Center, \\ Augusta, GA, USA
}

\begin{abstract}
Obinutuzumab is a novel glycoengineered type II anti-CD20 monoclonal antibody with a higher affinity for CD20 epitope, enhanced antibody-dependent cellular cytotoxicity and direct cell death, leading to superior cytotoxicity compared with rituximab. The approval of obinutuzumab by US Food and Drug Administration was based on a pivotal, phase III, randomized trial of chlorambucil monotherapy $(n=118)$, chlorambucil plus obinutuzumab $(n=333)$, or chlorambucil plus rituximab $(\mathrm{n}=330)$ in previously untreated patients with CLL. Obinutuzumab was administered intravenously as $1,000 \mathrm{mg}$ on days 1,8 , and 15 of cycle 1 and day 1 of subsequent cycles. Obinutuzumab plus chlorambucil was associated with an overall response rate of $78 \%$ and a median progression-free survival of 26.7 months. Overall, obinutuzumab was fairly well tolerated in this pivotal study. The incidence of grade 3 or higher adverse events was infusionrelated reactions $(20 \%)$, neutropenia (33\%), thrombocytopenia $(10 \%)$, and infections $(7 \%)$. Obinutuzumab in combination with chlorambucil is a safe and effective new treatment option for previously untreated elderly patients with CLL. It should become the new standard of care for these patients with significant co-morbidities who are not candidates for fludarabine-based therapy. Obinutuzumab combination therapy with several agents that inhibit kinases involved in the B-cell receptor signaling pathway, as well as many other agents utilized in the frontline and relapsed/refractory setting, is currently under investigation. As the results from these studies become available, the role of obinutuzumab is expected to expand to other settings.
\end{abstract}

Keywords: obinutuzumab, untreated chronic lymphocytic leukemia, GA101, chlorambucil

\section{Introduction}

The American Cancer Society estimates 14,620 new cases of chronic lymphocytic leukemia (CLL) to be diagnosed in the USA in 2015 with approximately 4,650 deaths predicted to occur. ${ }^{1}$ CLL, the most common lymphoproliferative disorder in the Western countries, is characterized by progressive accumulation of mature lymphocytes in the peripheral blood, bone marrow, and lymphoid tissues. CLL usually manifests as lymphocytosis with characteristic phenotype on B-cells $\left(\mathrm{CD}^{+}\right.$and $\left.\mathrm{CD} 23^{+}\right){ }^{2}$ Two separate staging systems (Rai and Binet) have been created to establish prognostic implications for survival. While specific differences exist between these systems, they generally take into account the site of disease involvement, presence of anemia and thrombocytopenia. ${ }^{3,4}$ New prognostic factors have been recently identified with the advent of molecular profiling. Genomic features such as unmutated immunoglobulin heavy-chain variable (IGHV) status and cytogenetic abnormalities such as del (17p), TP53 mutation and expression of CD38, and zeta-chain-associated protein kinase (ZAP-70) are associated with poor prognosis, including shorter progression-free survival (PFS) and overall survival (OS). Recently, mutations in NOTCH1, SF3B1, and $B I R C 3$ genes were also found to be associated with poor prognosis. ${ }^{5}$ CLL is
Correspondence: Arpita Shah Department of Pharmacy, Georgia Regents University Medical Center/ University of Georgia College of Pharmacy, I I 20 I5th Street, BI-2I0I, Augusta, GA 30192, USA

Email arshah@gru.edu 
mainly a disease of the elderly population with a median age at diagnosis of 72 years. Clinical manifestation of CLL can vary from a long-term indolent disease to a rapidly progressive disease with OS ranging from months to decades; nonetheless, it remains an incurable disease with currently available therapies with the exception of hematopoietic stem cell transplantation. ${ }^{6}$

Management of CLL is usually reserved for patients with stage III or IV disease or those with bulky lymphadenopathy, hepatosplenomegaly, constitutional symptoms (fatigue, night sweats, fever without infection, weight loss), threatened end-organ function, progressive anemia (hemoglobin $[\mathrm{Hgb}]<10 \mathrm{~g} / \mathrm{dL}$ ) or thrombocytopenia (platelet $<100 \times 10^{9} / \mathrm{L}$ ). The choice of treatment depends on various factors such as patient fitness, clinical stage of the disease, cytogenetic abnormalities, prior therapies, and response to previous agents. ${ }^{5,7}$ The combination of fludarabine, cyclophosphamide, and rituximab (FCR) is currently recommended as first-line therapy for patients less than 70 years of age and without co-morbidities. Until recently, it was recommended that elderly patients (age $\geq 70$ years) or those with significant co-morbidities should receive rituximab in combination with chlorambucil as frontline therapy. ${ }^{5-11}$ Although the addition of rituximab to chlorambucil has improved PFS and complete response (CR) rates compared with chlorambucil monotherapy, it did not result in survival benefit. ${ }^{12}$ Other options include bendamustine, fludarabine or cyclophosphamide/ prednisone \pm rituximab, rituximab, cladribine, and chlorambucil. Elderly patients remain underrepresented in majority of the CLL studies, and available data have not shown superiority of one regimen over another until recently. Patients with del (17p) do not benefit from these regimens, and alemtuzumabcontaining regimens as well as some novel targeted therapies are the only effective options for these patients. ${ }^{5}$ Rituximab, the first monoclonal antibody against CD20 antigen expressed on the surface of the human B cells, was approved in 2010 for previously untreated CLL. Its discovery revolutionized the treatment of $\mathrm{CD} 20^{+}$lymphoproliferative disorders after its initial approval in 1997; however, majority of the patients with CLL will eventually relapse after rituximab-containing immunochemotherapy, which highlights the need for developing superior therapeutic options. ${ }^{13,14}$ Ofatumumab, a secondgeneration anti-CD20 monoclonal antibody, was approved in 2009 for refractory CLL and recently, in April 2014, for previously untreated CLL. ${ }^{15}$ On November 1, 2013, obinutuzumab, a third-generation anti-CD20 monoclonal antibody, became the first treatment approved with US Food and Drug Administration's (FDA) breakthrough designation for use in combination with chlorambucil as a first-line therapy for previously untreated CLL. ${ }^{16}$

\section{Pharmacology}

CD20 is expressed on B cells from pre-B-cell stage until postgerminal cells differentiate to become plasma cells. Because CD20 is neither shed nor internalized in normal B cells, it serves as an ideal target for mature B-cell malignancies such as CLL. ${ }^{6}$ Monoclonal antibodies generally have three possible mechanisms of action: 1) antibody-dependent cellular cytotoxicity (ADCC), 2) complement-dependent cytotoxicity (CDC), and 3) direct growth inhibition and apoptosis, also known as direct cell death (Figure 1). ${ }^{17}$ Anti-CD20 monoclonal antibodies are classified as type I or type II based on their mode of CD20 binding and primary mechanism for catalysis. Type I antibodies (rituximab and ofatumumab) cause translocation of CD20 into lipid rafts within the cell membrane, which results in efficient CDC, with ofatumumab exhibiting stronger CDC. ${ }^{18-20}$

Type II antibodies (obinutuzumab), however, do not provoke localization of CD20 into lipid rafts; hence, it results in 10-1,000-fold less potent CDC compared with type I antibodies. ADCC is mediated by interaction between $\mathrm{Fc}$ region of the anti-CD20 antibody and Fc $\gamma \mathrm{RIII} \alpha$ (expressed on various immune effector cells). Obinutuzumab is a type II humanized CD20 IgG1 monoclonal antibody with glycoengineered Fc region, which leads to 100 -fold greater ADCC compared with rituximab and ofatumumab. It also binds to CD20 epitope in a different space orientation and with a wider elbo-hinge angle compared with rituximab (Figure 2). Obinutuzumab also mediates phagocytosis and superior induction of direct cell death compared with rituximab. Unlike type I monoclonal antibodies, the activity of obinutuzumab does not depend on classic apoptotic pathways, so it may have the ability to overcome typical apoptosis resistance mechanisms..$^{21,22}$

\section{Pharmacokinetics}

Based on the population pharmacokinetics, mean volume of distribution, terminal clearance, and half-life of obinutuzumab are approximately $3.8 \mathrm{~L}, 0.09 \mathrm{~L} /$ day, and 28 days, respectively. The metabolism of obinutuzumab has not been clearly studied; however, antibodies are mainly cleared via catabolism. The elimination of obinutuzumab follows a complex, compartment model and consists of a linear and time-dependent, saturable, nonlinear clearance pathway. The time-dependent, nonlinear clearance pathway is predominant during therapy initiation, but as treatment continues, linear clearance pathway predominates, suggesting target drug-mediated deposition. ${ }^{18}$ The relationship 


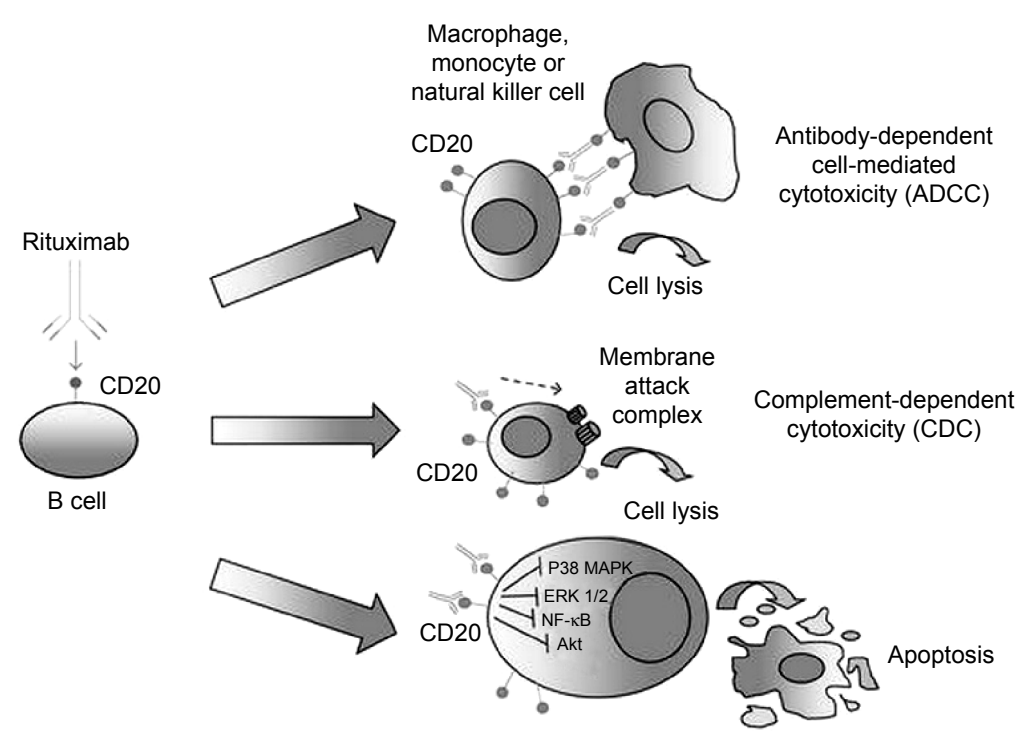

Figure I Schematic representation of the putative mechanisms mediating rituximab's anticancer activity in NHL cells.

Notes: The anti-CD20 monoclonal antibody rituximab has several mechanisms of action, including ADCC, which involves recruitment of effector cells, mediated by Fc $\gamma$ receptors, CDC, and apoptosis induction. Adapted from Motta G, Cea M, Moran E, et al. Monoclonal antibodies for non-Hodgkin's lymphoma: state of the art and perspectives. Clin Dev Immunol. 2010; doi: I0.1 155/2010/428253. ${ }^{45}$

between pharmacokinetics, clinical response and/or tumor burden has been inconclusive in Phase I/II trials, although Phase II studies reported worse response rates in patients with higher tumor burden, highlighting the importance of dosing schedule for optimal efficacy. ${ }^{23}$ The volume of distribution and steady-state clearance are expected to increase with body weight, but this is associated with minimal change in overall exposure; hence, dose modification is not recommended. Obinutuzumab has not been tested in patients with severe renal impairment $(\mathrm{CrCL} \leq 30 \mathrm{~mL} / \mathrm{min})$ and those

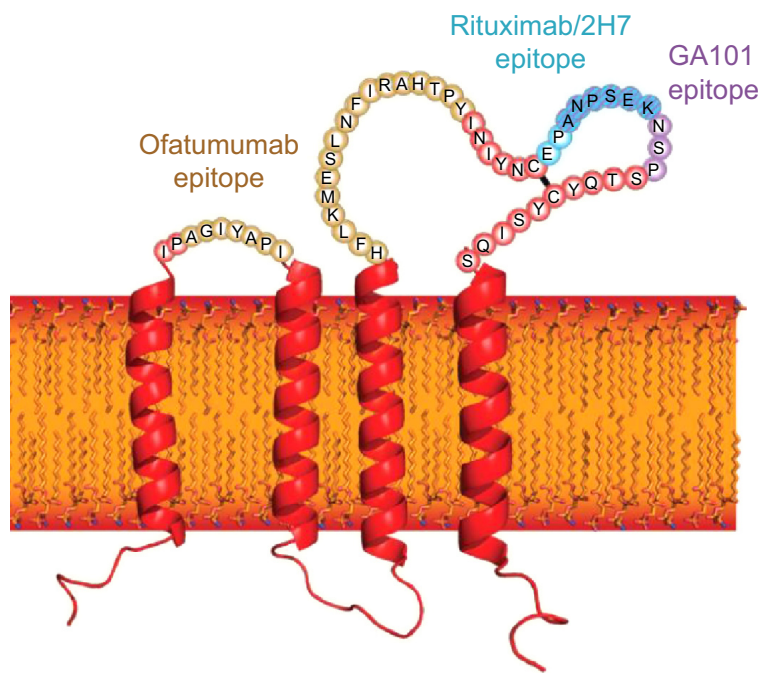

Figure 2 The structure and topology of CD20 and the epitopes recognized by rituximab, ofatumumab, and obinutuzumab.

Note: Adapted from Klein C, Lammens A, Schäfer W, et al. Epitope interactions of monoclonal antibodies targeting CD20 and their relationship to functional properties. MABs. 20I 3;5(I):22-31. ${ }^{20}$ with hepatic impairment; however, dose modifications are not expected since monoclonal antibodies are expected to be cleared via proteolytic enzymes. ${ }^{16}$

\section{Therapeutic potential of obinutuzumab}

In vitro studies comparing rituximab and obinutuzumab have demonstrated variable responses to individual CLL sample, although CLL cell depletion from whole blood by obinutuzumab was consistently stronger than rituximab. ${ }^{2,18}$ Several Phase I/II studies have demonstrated clinical activity of obinutuzumab in CLL (Table 1). In a Phase I study of 22 heavily pretreated patients with relapsed non-Hodgkin's lymphoma or CLL, obinutuzumab (200-2,000 mg) was administered as induction therapy weekly for 4 weeks. Patients who did not progress after induction therapy continued to receive obinutuzumab every 3 months for a maximum of eight doses. Five patients had CLL, all of whom were refractory to prior fludarabine therapy and received a median of four prior therapies. Separate results for patients with CLL are not available. At the end of induction, obinutuzumab therapy yielded a partial response (PR) of $23 \% .^{24}$

In the Phase Ib Galton study, a total of 41 previously untreated patients with CLL were randomized to receive obinutuzumab plus fludarabine and cyclophosphamide $(n=21)$ or bendamustine $(n=20)$ for six 28-day cycles. Obinutuzumab in combination with fludarabine and cyclophosphamide yielded an overall response rate $(\mathrm{ORR})$ of $62 \%(\mathrm{CR}=10 \%)$ compared with $90 \%(\mathrm{CR}=20 \%)$ when combined with bendamustine. With the 
Table I Efficacy of obinutuzumab in CLL

\begin{tabular}{|c|c|c|c|c|}
\hline Trial & Phase & $\begin{array}{l}\mathbf{n} \text { (type of patient } \\
\text { population) }\end{array}$ & $\begin{array}{l}\text { Obinutuzumab dosage } \\
\text { and administration }\end{array}$ & Efficacy \\
\hline GAUGUIN ${ }^{23,27,28}$ & I & I3 (R/R CLL) & $\begin{array}{l}400-2,000 \mathrm{mg} \\
\text { Cycle I: days I and } 8 \\
\text { Cycles 2-8: day I }\end{array}$ & $\begin{array}{l}\text { ORR }=62 \% \\
\text { Median PFS }=\text { NR } \\
\text { Median DOR }=10.5 \text { months }\end{array}$ \\
\hline & II & 20 (R/R CLL) & $\begin{array}{l}\mathrm{I}, 000 \mathrm{mg} \\
\text { Cycle I: days I, 8, and I5 } \\
\text { Cycles 2-8: day I }\end{array}$ & $\begin{array}{l}\text { ORR }=30 \% \\
\text { Median PFS }=10.7 \text { months } \\
\text { Median DOR }=8.9 \text { months }\end{array}$ \\
\hline GAUSS ${ }^{24}$ & I & $22(\mathrm{R} / \mathrm{R}$ CLL, $\mathrm{n}=5)$ & $\begin{array}{l}\text { Induction: } 200-2,000 \text { weekly } \\
\times 4 \text { weeks } \\
\text { Maintenance: every } 3 \text { months for maximum of } \\
\text { eight doses in patients with CR or PR at the } \\
\text { end of induction (same dose as induction) }\end{array}$ & $\mathrm{PR}=23 \%$ \\
\hline GALTON $^{25,26}$ & $\mathrm{lb}$ & $\begin{array}{l}\text { 4I (previously } \\
\text { untreated CLL) }\end{array}$ & $\begin{array}{l}\text { Cycle I: } 100 \mathrm{mg} \text { day I, } 900 \mathrm{mg} \text { day } 2 \\
\mathrm{I}, 000 \mathrm{mg} \text { days } 8 \text { and I5 } \\
\text { Cycles } 2-6: \mathrm{I}, 000 \mathrm{mg} \text { day I }\end{array}$ & $\begin{array}{l}\text { Obinutuzumab plus } \\
\text { fludarabine and } \\
\text { cyclophosphamide } \\
\text { - ORR }=62 \%(C R=10 \%) \\
\text { Obinutuzumab plus } \\
\text { bendamustine } \\
\text { - ORR }=90 \%(C R=20 \%)\end{array}$ \\
\hline CLLIII1 & III & $\begin{array}{l}781 \text { (untreated CLL } \\
\text { in elderly) }\end{array}$ & $\begin{array}{l}1,000 \mathrm{mg} \\
\text { Cycle I: days I, 8, and } 15 \\
\text { Cycles 2-6: day I }\end{array}$ & See Table 3 \\
\hline GAGE $^{30}$ & II & 89 (untreated CLL) & $\begin{array}{l}\text { I,000 mg cohort: } \\
\text { Cycle I: } 100 \mathrm{mg} \text { day I, } 900 \mathrm{mg} \text { day } 2 \text {, } \\
\text { I,000 mg days } 8 \text { and I } 5 \\
\text { Cycles } 2-8: 1,000 \mathrm{mg} \text { day I } \\
2,000 \mathrm{mg} \text { cohort: } \\
\text { Cycle I: } 100 \mathrm{mg} \text { day I, } 900 \mathrm{mg} \text { day } 2 \text {, } \\
\text { I,000 mg day } 3 \text {, and } 2,000 \mathrm{mg} \text { days } 8 \\
\text { and I5 } \\
\text { Cycles } 2-8: 2,000 \mathrm{mg} \text { day I }\end{array}$ & $\begin{array}{l}\text { I,000 mg cohort: } \\
\text { ORR }=49 \% \\
2,000 \mathrm{mg} \text { cohort: } \\
\text { ORR }=67 \%(P=0.08)\end{array}$ \\
\hline
\end{tabular}

Notes: aRepresents all doses administered intravenously.

Abbreviations: CLL, chronic lymphocytic leukemia; R/R CLL, relapsed/refractory chronic lymphocytic leukemia; NR, not reported; DOR, duration of response; ORR, overall response rate; PFS, progression-free survival; PR, partial response.

median follow-up of 23.5 months in one cohort and 20.7 months in the other cohort, none of the patients have relapsed or died. This study confirmed that obinutuzumab could be safely administered with standard chemotherapeutic regimens for the treatment of previously untreated patients with CLL. ${ }^{25,26}$

GAUGUIN was a Phase I/II study that evaluated the safety and efficacy of obinutuzumab monotherapy in heavily pretreated patients (median of three prior therapies) with relapsed/refractory (R/R) CLL. In the Phase I dose escalation study, obinutuzumab was administered to 13 patients as a flat dose ranging from $400 \mathrm{mg}$ to $2,000 \mathrm{mg}$ (days 1 and 8 of cycle 1 ; day 1 of cycles $2-8$ ). Approximately $33 \%$ of the patients had high-risk cytogenetics (del [17p] or del [11q]) and approximately $70 \%$ of the patients had unmutated IGHV status. Obinutuzumab monotherapy yielded an ORR of $62 \%$, all of which were PRs. The median duration of response (DOR) was 10.5 months at 38.7 months follow-up. Based on the preliminary efficacy data as well as modeling and simulation of pharmacokinetic data, which showed faster elimination of obinutuzumab in the first cycle than later cycles, a higher dose was selected for Phase II study. Obinutuzumab was administered as 1,000 mg intravenously (days 1, 8, and 15 of cycle 1; day 1 of cycle 2-8) for ten infusions to a total of 20 patients with R/R CLL. Of the 16 evaluable patients, the best ORR was $30 \%$ with one patient achieving a CR. At a median follow-up of 28.8 months, median PFS and median DOR in responders were 10.7 months and 8.9 months, respectively. Less-impressive response rates in the Phase II of this study were thought to be related to higher tumor burden of enrolled patients, suggesting that doses higher than 1,000 mg may be necessary in this specific patient population. Similar to outcomes seen with ofatumumab, a trend for a dose-response relationship was seen in Phase I of this study. Based on all the available clinical data in B-cell malignancies in Phase I/ II studies as well as modeling and simulation, a flat dose of $1,000 \mathrm{mg}$ was chosen to be administered on days 1,8 , and 
15 of the first cycle for Phase III studies to rapidly achieve and maintain adequate drug levels. ${ }^{23,27-29}$

Since earlier Phase I/II studies suggested a dose-response relationship with obinutuzumab, GAGE study (Phase II) was designed to evaluate the safety and efficacy of two doses of obinutuzumab in 80 patients with previously untreated CLL. Of the enrolled patients, 54\% had unmutated IGHV status and $10 \%$ had del (17p). Obinutuzumab was administered as $1,000 \mathrm{mg}$ (100 mg day $1 ; 900 \mathrm{mg}$ day $2 ; 1,000 \mathrm{mg}$ days 8 and 15 of cycle $1 ; 1,000 \mathrm{mg}$ day 1 of cycles $2-8)$ or $2,000 \mathrm{mg}$ (100 $\mathrm{mg}$ day $1 ; 900 \mathrm{mg}$ day $2 ; 1,000 \mathrm{mg}$ day $3 ; 2,000 \mathrm{mg}$ days 8 and 15 of cycle $1 ; 2,000 \mathrm{mg}$ day 1 of cycles 2-8) every 21 days. Preliminary analysis at 11 months showed an ORR of $49 \%$ and $67 \%$ in patients receiving obinutuzumab $1,000 \mathrm{mg}$ and $2,000 \mathrm{mg}$, respectively $(P=0.08){ }^{30}$

CLL11 was a Phase III, randomized, controlled, openlabel study that enrolled 781 previously untreated patients with CLL with co-morbidities in a three-arm, two-stage trial. The study was conducted to assess whether the addition of either rituximab or obinutuzumab could enhance the efficacy of chlorambucil monotherapy in elderly, previously untreated patients with CLL. Notable eligibility criteria included a Cumulative Illness Rating Scale (CIRS) total score $>6$ or $\mathrm{CrCl}$ of 30-69 mL/min. Notable exclusion criteria included inadequate liver function, positive hepatitis (hepatitis B or C) serology, or immunization to live vaccine within 28 days prior to randomization. Patients were randomized to receive either obinutuzumab plus chlorambucil (G-Clb; stage 1, $\mathrm{n}=238$; stage $2, n=333$ ) or rituximab plus chlorambucil ( $\mathrm{R}-\mathrm{Clb}$; stage $1, n=233$; stage $2, n=330$ ) or chlorambucil alone (stage 1 , $\mathrm{n}=118$ ) in six 28-day cycles. Chlorambucil was administered orally at a dose of $0.5 \mathrm{mg} / \mathrm{kg}$ on days 1 and 15 of each cycle. Obinutuzumab was administered intravenously as $1,000 \mathrm{mg}$ on days 1,8 , and 15 of cycle 1 and on day 1 of cycles 2-6. To ameliorate the infusion-related reactions (IRRs) seen in $89 \%$ of the first 53 patients receiving obinutuzumab in an earlier study, the protocol was amended to administer first obinutuzumab infusion over 2 days. The first dose was split between day 1 (100 mg) and day 2 (900 mg) and was administered to $42 \%$ of the patients. Rituximab was administered intravenously at $375 \mathrm{mg} / \mathrm{m}^{2}$ on day 1 of cycle 1 and $500 \mathrm{mg} / \mathrm{m}^{2}$ on day 1 of cycles $2-6$. Dose modifications were not permitted. Enrolled patients represented a homogenous population that is representative of majority of the new CLL diagnoses. The median age of enrolled patients was 73 years. Of note, approximately $60 \%$ of the patients in each group had unmutated IGHV status. ${ }^{31}$ The primary endpoint of the study was PFS, and key secondary endpoints included response rates, minimal residual disease, and OS. At 3 months after the end of treatment, compared with chlorambucil monotherapy, the median PFS was significantly prolonged for patients receiving obinutuzumab and chlorambucil (11.1 months vs 26.7 months, hazard ratio $[\mathrm{HR}]=0.18, P<0.001)$ and those receiving rituximab and chlorambucil (11.1 months vs 16.3 months, HR $=0.44, P<0.001)$. Similar benefit was seen in all subgroups except in patients with del (17p). G-Clb resulted in significantly prolonged PFS compared with $\mathrm{R}-\mathrm{Clb}$ (HR $=0.39, P<0.001)$. The OS was also prolonged in patients receiving $\mathrm{G}-\mathrm{Clb}$ compared with those receiving chlorambucil alone (rates of death: $20 \%$ vs $9 \%, \mathrm{HR}=0.41$, $P=0.002)$. Survival benefit with $\mathrm{G}-\mathrm{Clb}$ over $\mathrm{R}-\mathrm{Clb}$ was not observed (HR $=0.66, P=0.08)$; however, longer follow-up may be required to observe the mortality benefit. Median OS was not reached in either of the combination therapy arms. G-Clb yielded higher overall, complete, and molecular response rates compared with $\mathrm{R}-\mathrm{Clb}$ (Table 2). ${ }^{31}$ Results of this pivotal trial led to the approval of obinutuzumab by FDA in November 2013.

Updated analysis of CLL11 with a data cutoff of April 2014 was recently published. As seen in the earlier analysis, the median PFS continued to remain significantly prolonged with G-Clb compared with R-Clb (29.2 vs 15.4 months, $\mathrm{HR}=0.40, P<0.001)$. Updated analysis, however, did not show any significant difference in OS between $\mathrm{G}-\mathrm{Clb}$ and $\mathrm{R}-\mathrm{Clb}(\mathrm{HR}=0.70, P=0.06)$. This is likely secondary to the small number of death events in both arms (45 of 333 patients died in the G-Clb arm; 63 of 330 patients died in the $\mathrm{R}-\mathrm{Clb}$ arm); hence, the data still may require further follow-up to show mortality benefit between the anti-CD20 monoclonal antibodies. Previously observed OS benefit of G-Clb over chlorambucil monotherapy was again confirmed (HR $=0.47, P=0.0014$ ); however, unlike previous analysis, updated analysis showed prolonged OS with $\mathrm{R}-\mathrm{Clb}$ compared with chlorambucil monotherapy ( $\mathrm{HR}=0.60, P=0.0242)$. Even though majority of the patients initially receiving chlorambucil monotherapy crossed over to either G-Clb or $\mathrm{R}-\mathrm{Clb}$ arm as next-line agents, mortality benefit of G-Clb and R-Clb over chlorambucil monotherapy was still maintained. Time to next antileukemic treatment was longer with G-Clb compared with R-Clb (42.7 vs 32.7 months, $\mathrm{HR}=0.54$, $P<0.001) .{ }^{32}$ A separate subgroup analysis of CLL11 was conducted to evaluate the efficacy and safety of obinutuzumab in the setting of R/R CLL. A total of 30 patients who initially received chlorambucil monotherapy developed progressive CLL within 6 months of chlorambucil monotherapy were treated with $\mathrm{G}-\mathrm{Clb}$ (dosage and administration same as 
Table 2 Efficacy and safety outcomes from CLLII

\begin{tabular}{|c|c|c|}
\hline & $\begin{array}{l}\text { Chlorambucil plus rituximab } \\
\text { (safety analysis: } n=321 \text { ) } \\
\text { (efficacy analysis: } n=333 \text { ) }\end{array}$ & $\begin{array}{l}\text { Chlorambucil plus obinutuzumab } \\
\text { (safety analysis: } n=336 \text { ) } \\
\text { (efficacy analysis: } n=330 \text { ) }\end{array}$ \\
\hline \multicolumn{3}{|l|}{ Efficacy } \\
\hline \multirow[t]{2}{*}{ Median PFS, months } & 15.2 & 26.7 \\
\hline & \multicolumn{2}{|c|}{$P$-value $<0.002$} \\
\hline \multirow[t]{2}{*}{ Median OS, months } & NR & NR \\
\hline & \multicolumn{2}{|c|}{$P$-value $=0.09$} \\
\hline ORR, \% & 65 & 78 \\
\hline CR rate, $\%$ & 7 & 21 \\
\hline \multicolumn{3}{|l|}{ MRD negative, \% } \\
\hline Bone marrow & 2.6 & 19.5 \\
\hline Blood & 3.3 & 37.7 \\
\hline \multicolumn{3}{|l|}{ Grade $3-5$ adverse events } \\
\hline Overall, \% & 55 & 70 \\
\hline Neutropenia, \% & 28 & 33 \\
\hline Anemia, \% & 4 & 4 \\
\hline Thrombocytopenia, \% & 3 & 10 \\
\hline Leukopenia, \% & I & 4 \\
\hline Infections, \% & 7 & 7 \\
\hline Infusion-related reactions, \% & 4 & 20 \\
\hline
\end{tabular}

Note: Adapted from Shah A. Obinutuzumab: a novel anti-CD20 monoclonal antibody for previously untreated chronic lymphocytic leukemia. Ann Pharmacother. 2014;48(10): 1356-61. doi: 10.1177/1060028014543271.46

Abbreviations: CLL, chronic lymphocytic leukemia; PFS, progression-free survival; OS, overall survival; NR, not reported; CR, complete response; ORR, overall response rate; MRD, minimal residual disease.

CLL11) for six cycles. At the end of the treatment, the ORR was $87 \%(\mathrm{CR}=7 \%$, incomplete $\mathrm{CR}=3 \%$, and $\mathrm{PR}=77 \%)$, and the PFS was 17.2 months. The results of this subgroup analysis suggest the role of $\mathrm{G}-\mathrm{Clb}$ for patients with $\mathrm{CLL}$ who have failed prior chlorambucil monotherapy. ${ }^{33}$

\section{Safety}

Overall, obinutuzumab is fairly well tolerated with the most common adverse events (AEs) being IRRs and hematological toxicities. In one of the Phase I studies, the most common grade 3-4 AEs included neutropenia (48\%-55\%) and IRRs (20\%) ${ }^{26}$ In the Phase II part of the GANGUIN trial, obinutuzumab was well tolerated with no dose-limiting toxicities reported over the 400-2,000 $\mathrm{mg}$ dose range. The most common AEs included IRRs (any grade $=95 \%$; grade $3=30 \%$ ), all of which occurred during the first infusion. Grade 3-4 hematological AEs included neutropenia (25\%) and thrombocytopenia (15\%). Of note, in Phase I/ II GANGUIN study, both early-and late-onset neutropenia were reported. Of the 13 patients with grade $3-4$ neutropenia, six had a first onset within 30 days of treatment exposure. Infections were reported in $30 \%$ of the patients; however, only $15 \%$ of all infections were grade 3 (bacterial, herpes zoster, and testicular abscess). None of the infections were grade $4 .{ }^{23}$
Higher dose of obinutuzumab has not been associated with any additional safety concerns. In the Phase I/II GAGE trial, obinutuzumab 2,000 $\mathrm{mg}$ dosing schema was associated with grade 3-4 IRR of $11 \%$ compared with $23 \%$ associated with the standard, FDA approved, 1,000 mg dosing schema. The reason why higher dose was associated with a lower incidence of IRR remains to be investigated. The incidence of grade 3-4 neutropenia and infections was similar between both dosing schemas. ${ }^{30}$

In the CLL11 trial, the most frequent grade 3 or higher AEs in the G-Clb arm included IRRs (20\%), infections (12\%), and hematological AEs such as neutropenia (33\%), thrombocytopenia (10\%), anemia (4\%), and leukopenia (4\%) (Table 2). The incidence of these AEs was similar with R-Clb except for lower rates of thrombocytopenia (3\%) and IRRs (4\%). With regards to grade 3-4 infections, no significant differences were found between three treatment arms despite a higher incidence of neutropenia with G-Clb. All grade 3-4 IRRs occurred during the first infusion of obinutuzumab, which led to discontinuation of therapy in $8 \%$ of the patients. The incidence of IRRs decreased significantly with subsequent therapy, $3 \%$ with second dose and $<1 \%$ with subsequent doses. No grade 3-4 IRRs were reported beyond first dose. Of note, no significant difference in the IRRs was seen between G-Clb and R-Clb arms in the 
stage II of CLL11 trial; however, the incidence was higher in G-Clb group compared with R-Clb group (20\% vs 4\%, respectively). First administration of obinutuzumab has been shown to trigger immediate and strong release of cytokines (IL6, IL8, TNF $\alpha$, IFN $\gamma$, and IL10) associated with a rapid destruction of circulating $\mathrm{B}$ cells, hence demonstrating a close temporal relationship between the release of cytokines and development of IRRs. When compared with rituximab, obinutuzumab results in more potent cytotoxicity and rapid B-cell depletion. ${ }^{23,34}$ In an exploratory analysis of CLL11 evaluating risk factors associated with IRR, type of treatment received, tumor burden, target antigen expression, and $\mathrm{FC} \gamma \mathrm{R}$ gene polymorphism were identified as potential risk factors. Patients with high tumor burden and/or high circulating lymphocyte count $\left(>25 \times 10^{9} / \mathrm{L}\right)$ are at risk for tumor lysis syndrome and should receive appropriate pharmacologic prophylaxis. ${ }^{35}$ In the pivotal trial, the incidence of tumor lysis syndrome was higher with obinutuzumab (4\%) compared with rituximab $(<1 \%)$. Other serious AEs included newly diagnosed neoplasms; however, the rates were comparable with both monoclonal antibodies. Updated analysis in April 2014 did not reveal any new safety concerns. A total of $4 \%$ of the patients died in the G-Clb arm due to AEs compared with $6 \%$ in the R-Clb arm. ${ }^{31,32}$

Obinutuzumab labeling includes a black box warning for hepatitis $\mathrm{B}$ reactivation and progressive multifocal leukoencephalopathy. Anti-CD20 monoclonal antibodies are associated with the highest risk of hepatitis $\mathrm{B}$ reactivation; hence, patients should be screened for risk of hepatitis B reactivation, and if at risk, antiviral therapy should be initiated to prevent this potentially fatal complication. ${ }^{16,36}$

\section{Dosage and administration}

Obinutuzumab is administered as an intravenous infusion for six 28-day cycles. The total dose is $1,000 \mathrm{mg}$ with the exception of the first dose for cycle 1 , which should be administered as $100 \mathrm{mg}$ on day 1 and $900 \mathrm{mg}$ on day 2. The first dose of the first cycle should be administered at $25 \mathrm{mg} / \mathrm{h}$. Similar to rituximab, the second dose of cycle one can be titrated up to $50 \mathrm{mg} / \mathrm{h}$ every 30 minutes to a maximum rate of $400 \mathrm{mg} / \mathrm{h}$. Subsequent infusions can be started at $100 \mathrm{mg} / \mathrm{h}$ and increased by $100 \mathrm{mg} / \mathrm{h}$ every 30 minutes up to a maximum rate of $400 \mathrm{mg} / \mathrm{h}$. All patients should be premedicated with acetaminophen $(650-1000 \mathrm{mg})$, intravenous glucocorticoid (dexamethasone $20 \mathrm{mg}$ or methylprednisolone $80 \mathrm{mg}$ ), and an antihistamine (diphenhydramine $50 \mathrm{mg}$ ) prior to the first two infusions. For subsequent infusions, premedication with an antihistamine, for history of grade $\geq 1$ IRR, and intravenous glucocorticoid, for history of grade $\geq 3$ IRR, or a lymphocyte count $>25 \times 10^{9} / \mathrm{L}$, is recommended..$^{16}$

\section{Formulary considerations}

Obinutuzumab is supplied as a 1,000-mg single-use vial, which is recommended to be diluted in adequate amount of $0.9 \%$ sodium chloride to yield a final concentration of $0.4-4 \mathrm{mg} / \mathrm{mL}$. Diluted solution for infusion should be used immediately; however, it can be stored up to 24 hours at $2^{\circ} \mathrm{C}-8^{\circ} \mathrm{C}$ followed by 48 hours at room temperature. ${ }^{16}$ The current average wholesale prices for $1,000 \mathrm{mg}$ of obinutuzumab (single vial) and rituximab (two 500-mg vials) are US\$6,192 and US\$8,233, respectively. ${ }^{37}$ For a person with a body surface area of $2 \mathrm{~m}^{2}$, the cost of obinutuzumab for the first cycle will be approximately $56 \%$ higher than that of rituximab; however, the overall cost is fairly similar for six cycles of treatment duration.

\section{Conclusion}

Obinutuzumab is approved by US FDA for use in combination with chlorambucil in previously untreated patients based on the results of CLL11. Obinutuzumab in combination with chlorambucil should be considered the new standard of care for previously untreated patients with CLL with co-morbidities that are not eligible for fludarabine-based therapies as it is the first study to show survival benefit over another regimen in this patient population. The response rates, however, remain grim for patients with del (17p); hence, ibrutinib, a Bruton's Tyrosine Kinase inhibitor, remains an important treatment option as frontline therapy for patients with del (17p). However, it is associated with an increased risk of atrial fibrillation and bleeding complications. ${ }^{5}$

Combination chemoimmunotherapy with FCR is associated with an ORR of $90 \%(C R=44 \%)$ and median PFS of 4.8 years; hence, it remains the standard of care for previously untreated, younger, fit patients. ${ }^{5-11}$ Whether the substitution of obinutuzumab for rituximab in the FCR regimen results in better outcomes is currently under investigation (NCT01300247). Obinutuzumab-based combination therapies are being studied as frontline and salvage therapy for $\mathrm{R} / \mathrm{R}$ CLL (Table 3) as well as other subtypes of non-Hodgkin's lymphomas. Compared with chlorambucil monotherapy, bendamustine and alemtuzumab in combination with rituximab have yielded superior response rates and PFS in previously untreated elderly patients with CLL. Alemtuzumab monotherapy has also shown superior outcomes in patients with del (17p) compared with chlorambucil monotherapy. Several 
Table 3 Ongoing or planned studies of obinutuzumab in CLL

\begin{tabular}{|c|c|c|c|c|}
\hline$\frac{\text { Clinicaltrials.gov }}{\text { NCT Identifier }}$ & Phase & Regimen & Study population & Status \\
\hline NCT02225275 & NR & Obinutuzumab plus lenalidomide & Recurrent CLL/SLL & Not yet accruing \\
\hline NCT0237I590 & $\mathrm{I} / \mathrm{II}$ & Obinutuzumab plus lenalidomide & Previously untreated CLL/SLL & Not yet accruing \\
\hline NCT0I980875 & III & $\begin{array}{l}\text { Obinutuzumab plus idelalisib versus } \\
\text { obinutuzumab plus chlorambucil }\end{array}$ & Previously untreated CLL & Not yet accruing \\
\hline NCT02406742 & $I / I I$ & $\begin{array}{l}\text { CC- } 122 \text { monotherapy, CC-I } 22 \text { plus rituximab, } \\
\text { ibrutinib or obinutuzumab }\end{array}$ & R/R CLL/SLL & Not yet accruing \\
\hline NCTOI 644253 & $\mathrm{lb}$ & TRU-0I6 plus rituximab or obinutuzumab & $\begin{array}{l}\text { Three cohorts enrolling previously } \\
\text { untreated CLL patients and I cohort } \\
\text { enrolling patients with R/R CLL }\end{array}$ & Accruing \\
\hline NCT02292225 & $\mathrm{lb}$ & Duvelisib plus obinutuzumab & $\begin{array}{l}\text { R/R CLL previously treated with a } \\
\text { BTK inhibitor }\end{array}$ & Accruing \\
\hline NCT02264574 & III & $\begin{array}{l}\text { Ibrutinib plus obinutuzumab versus obinutuzumab } \\
\text { plus chlorambucil }\end{array}$ & Previously untreated CLL/SLL & Accruing \\
\hline NCT0I4I4205 & II & Obinutuzumab I,000 mg versus $2,000 \mathrm{mg}$ & Previously untreated CLL & $\begin{array}{l}\text { Ongoing, not } \\
\text { accruing }\end{array}$ \\
\hline NCT02320487 & II & Obinutuzumab plus bendamustine & Previously untreated CLL & Accruing \\
\hline NCT0I905943 & Illb & $\begin{array}{l}\text { Obinutuzumab versus Obinutuzumab } \\
\text { plus fludarabine, cyclophosphamide, and } \\
\text { bendamustine or obinutuzumab plus chlorambucil }\end{array}$ & $\begin{array}{l}\text { Previously untreated or relapsed/ } \\
\text { refractory CLL }\end{array}$ & Accruing \\
\hline NCT0207I 225 & II & Obinutuzumab and bendamustine & Refractory or relapsed CLL & Accruing \\
\hline NCT0I685892 & $\mathrm{lb}$ & Obinutuzumab and GDC-1099 (ABT-199) & $\begin{array}{l}\text { Previously untreated or relapsed/ } \\
\text { refractory CLL }\end{array}$ & Accruing \\
\hline NCT0I4I4205 & II & Obinutuzumab $\mathrm{I}, 000 \mathrm{mg}$ versus $2,000 \mathrm{mg}$ & Previously untreated CLL & $\begin{array}{l}\text { Ongoing, not } \\
\text { accruing }\end{array}$ \\
\hline NCT02I 00852 & $\mathrm{l} / \mathrm{llb}$ & Obinutuzumab plus TGR-I 202 plus chlorambucil & CLL (exact population not defined) & Accruing \\
\hline NCTOI300247 & $\mathrm{lb}$ & $\begin{array}{l}\text { Obinutuzumab plus bendamustine or fludarabine } \\
\text { and cyclophosphamide }\end{array}$ & Previously untreated & $\begin{array}{l}\text { Ongoing, not } \\
\text { accruing }\end{array}$ \\
\hline NCT02229422 & $\mathrm{I} / \mathrm{II}$ & $\begin{array}{l}\text { Obinutuzumab plus high-dose } \\
\text { methylprednisolone }\end{array}$ & Previously untreated & Accruing \\
\hline NCT02296918 & 1 & Obinutuzumab plus ACP-196 & $\begin{array}{l}\text { Cohort I: R/R CLL } \\
\text { Cohort 2: previously untreated }\end{array}$ & Accruing \\
\hline NCT023I 5768 & $\mathrm{Ib} / \mathrm{ll}$ & Ibrutinib plus obinutuzumab & $\begin{array}{l}\text { Previously untreated (over } 65 \text { years } \\
\text { of age or with co-morbidities) }\end{array}$ & $\begin{array}{l}\text { Not yet open } \\
\text { for accrual }\end{array}$ \\
\hline
\end{tabular}

Abbreviations: CLL, chronic lymphocytic leukemia; SLL, small lymphocytic lymphoma; NR, not reported; R/R, relapsed/refractory; BTK, Bruton's Tyrosine Kinase.

combinations of obinutuzumab and bendamustine are currently under evaluation in various stages of clinical trial; however, there are currently no trials evaluating efficacy and safety of alemtuzumab plus obinutuzumab, an important area of investigation for future. . $38-41^{-1}$

Increasing evidence shows that antigen-dependent and antigen-independent $\mathrm{B}$-cell receptor (BCR) signaling and proteins in the B-cell CLL/lymphoma 2 (Bcl-2) family play a central role in the pathogenesis of CLL. Understanding of this pathophysiology has recently led to the development and approval of two targeted kinase therapies, ibrutinib and idelalisib. ${ }^{38}$ Obinutuzumab combination therapy is under investigation with several agents that inhibit kinases involved in the BCR signaling pathway (Table 3 ).

Ofatumumab, a different anti-CD20 monoclonal antibody, was recently approved for use in combination with chlorambucil for previously untreated patients with CLL based on the results of a Phase III trial demonstrating an ORR of $82 \%$ and median PFS of 22.4 months. Ofatumumab plus chlorambucil (O-Clb) failed to show a survival benefit over chlorambucil monotherapy. ${ }^{42}$ Ladyzynski and colleagues recently published a Bayesian network meta-analysis of randomized clinical trials involving treatment-naive, symptomatic patients with CLL. Of all the treatment options evaluated in the network analysis (chlorambucil, fludarabine, $\mathrm{O}-\mathrm{Clb}$, R-Clb, and G-Clb), G-Clb was found to be the most effective therapy with respect to projected mean PFS and was associated with the highest potential of prolonging OS of patients. ${ }^{43}$ Reyes and colleagues recently presented results of a study comparing the cost-effectiveness of G-Clb versus $\mathrm{O}-\mathrm{Clb}$ using a Markov model. G-Clb use was associated with an increase of 0.83 life years and 0.79 quality-adjusted 
life year as well as US\$4,500 gain in incremental cost per quality-adjusted life years relative to $\mathrm{O}-\mathrm{Clb}$. Treatment with $\mathrm{O}-\mathrm{Clb}$ was higher by US $\$ 3,600$ per patient relative to $\mathrm{G}-\mathrm{Clb}$. This analysis suggested that treatment with G-Clb is highly cost-effective compared with O-Clb. ${ }^{44}$

As the place in therapy for obinutuzumab expands, headto-head comparison with ofatumumab in addition to other agents commonly used as frontline therapy and in relapsed/ refractory setting (bendamustine plus rituximab) will become critical. Except for CLL11, no other well-designed, randomized, Phase III trial to date has shown that targeting CD20 antigen in patients with CLL and coexisting conditions results in improved survival. Survival benefit was not seen when G-Clb and R-Clb were compared; however, G-Clb was superior in achieving better minimal residual disease negative, which has been predicted to be associated with longer OS in patients receiving fludarabine-based chemoimmunotherapy. With longer patient follow-up, this difference may become apparent. Results of ongoing studies will be critical in determining whether obinutuzumab in combination with targeted kinase inhibitors such as ibrutinib and idelalisib will further enhance efficacy without significant impact on AEs.

\section{Disclosure}

The author reports no conflicts of interest in this work.

\section{References}

1. American Cancer Society. Cancer Facts and Figures 2015. Atlanta, GA: American Cancer Society; 2015.

2. Desai A, El-Bakkar H, Abdul-Hay M. Novel agents in the treatment of chronic lymphocytic leukemia: a review about the future. Clin Lymphoma Myeloma Leuk. 2015;15(6):314-322.

3. Binet JL, Auquier A, Dighiero G, et al. A new prognostic classification of chronic lymphocytic leukemia derived from a multivariate survival analysis. Cancer. 1981;48:198-206.

4. Rai KR, Sawitsky A, Cronkite EP, Chanana AD, Levy RN, Pasternack BS. Clinical staging of chronic lymphocytic leukemia. Blood. 1975;46: 219-234.

5. National Comprehensive Cancer Network. Non-Hodgkin's Lymphoma. Version 2. 2015. NCCN Clinical Practice Guidelines in Oncology. Available from: www.nccn.org. Accessed March 1, 2015.

6. Jaglowski SM, Alinari L, Lapalombella R, Muthusamy N, Byrd JC. The clinical application of monoclonal antibodies in chronic lymphocytic leukemia. Blood. 2010;116(19):3705-3714.

7. Hallek M. Chronic lymphocytic leukemia: 2013 update on diagnosis, risk stratification and treatment. Am J Hematol. 2013;88:804-816.

8. Cheson BD. Monoclonal antibody therapy of chronic lymphocytic leukemia. Best Pract Res Clin Hematol. 2010;23:133-143.

9. Hallek M, Fingerle-Rowson G, Fink A-M, et al. First-line treatment with fludarabine, cyclophosphamide, and rituximab improves overall survival in previously untreated patients with advanced chronic lymphocytic leukemia: results of a randomized phase III trial on behalf of an International Group of Investigators and the German CLL Study Group. Blood. 2009;114(22):535. [ASH Annual Meeting Abstracts].
10. Eichhorst B, Dreyling M, Robak T, Monteserrat E, Hallek M. Chronic lymphocytic leukemia: ESMO clinical practice guidelines for diagnosis, treatment and follow up. Ann Oncol. 2011;22(suppl 6):vi50-vi54.

11. Fischer KJ, Bahlo AM, Fink R, et al. Extended follow up of the CLL8 protocol, a randomized phase III trial of the German CLL Study Group comparing fludarabine and cyclophosphamide (FC) to FC plus rituximab (FCR) for previously untreated patients with CLL: results on survival, progression free survival, delayed neutropenia and secondary malignancies confirm superiority of FCR regimen. Blood. 2012;120:435. [ASH Annual Meeting Abstracts].

12. Hillmen P, Gribben JG, Follows GA, et al. Rituximab plus chlorambucil as first-line treatment for chronic lymphocytic leukemia: final analysis of an open-label phase II study. J Clin Oncol. 2014;32(12):1236-1241.

13. Roche Pharmaceutical Inc. Product Information. Rituximab (Rituxan). South San Francisco, CA: Roche Pharmaceutical Inc; 1997.

14. Cartron G, Trappe RU, Solal-Celigny P, Hallek M. Interindividual variability of response to rituximab: from biological origins to individualized therapies. Clin Cancer Res. 2011;17(1):19-30.

15. Glaxo Group Limited. Product Information. Ofatumumab (Arzerra). Brentford, UK: Glaxo Group Limited; 2009.

16. Genentech Inc. Product Information. Obinutuzumab (Gazyva). South San Francisco: Genentech Inc; 2013.

17. Smolej L. Targeted treatment of chronic lymphocytic leukemia: clinical potential of obinutuzumab. Pharmgenomics Pers Med. 2014;8:1-7.

18. Cerquozzi S, Owen C. Clinical role of obinutuzumab in the treatment of naïve patients with chronic lymphocytic leukemia. Biologics. 2015;9:13-22.

19. Hoy S. Obinutuzumab: a review of its use in patients with chronic lymphocytic leukemia. Drugs. 2015;75:285-296.

20. Klein C, Lammens A, Schäfer W, et al. Epitope interactions of monoclonal antibodies targeting CD20 and their relationship to functional properties. MABs. 2013;5(1):22-31.

21. Golay J, Da Roit F, Bologna L, et al. Glycoengineered CD20 antibody obinutuzumab activates neutrophils and mediates phagocytosis through CD16B more efficiently than rituximab. Blood. 2013; 122(20):2482-2491.

22. Rafiq S, Butchar JP, Cheney C, et al. Comparative assessment of clinically utilized CD-20 directed antibodies in chronic lymphocytic leukemia cells reveals divergent NK cell, monocyte, and macrophage properties. J Immunol. 2013;190:2702-2711.

23. Cartron G, de Guibert S, Dilhuydy MS, et al. Obinutuzumab (GA101) in relapsed/refractory chronic lymphocytic leukemia: final data from the phase I/II GAUGUIN study. Blood. 2014;124(14):2196-2202.

24. Sehn LH, Assouline SE, Steart D. A phase 1 study of obinutuzumab induction followed by 2 years of maintenance in patients with relapsed CD20-positive B-cell malignancies. Blood. 2012;119(22): $5118-5125$.

25. Brown JR, O'Brien S, Kingsley CD, et al. Safety and efficacy of obinutuzumab with fludarabine/cyclophosphadmide or bendamustine in the initial therapy of patients with chronic lymphocytic leukemia: results from phase $1 \mathrm{~b}$ Galton trial (GA04779g). [abstract 523]. In: 55th American Society of Hematology Annual Meeting and Exposition. San Francisco, 2013.

26. Brown JR, O'Brien S, Kingsley CD, et al. Obinutuzumab (G) plus fludarabine/cyclophosphamide (F-GC) or bendamustine (G-B) in the initial therapy of CLL patients: the phase 1b GALTON trial. Blood. 2015;125(18):2279-2785.

27. Cartron G, de Guibert S, Dilhuydy MS, et al. Phase I study of RO5072759 (GA101) in relapsed/refractory chronic lymphocytic leukemia. Blood. 2009;114(22):884. [ASH Annual Meeting Abstracts].

28. Cartron G, Morschhauser F, Thieblemont C, et al. Results from a phase II study of obinutuzumab monotherapy in relapsed/refractory CLL [abstract]. Haematologica. 2011;96(suppl 2):39. [Abstract 0101].

29. Morschhauser F, Salles G, Cartron G, et al. Dose selection for phase III studies of the monoclonal anti-CD20 antibody obinutuzumab (GA101) a rational approach. Haematologica. 2011;96(suppl 2):390. 
30. Flynn JM, Byrd JC, Kipps TJ, et al. Obinutuzumab (GA101) 1,000 mg versus $2,000 \mathrm{mg}$ in patients with chronic lymphocytic leukemia (CLL): results of the phase II GAGE (GA04768g) trial. J Clin Oncol. 2014;32(suppl 5): abstract 7083.

31. Goede V, Fischer K, Busch R, et al. Obinutuzumab plus chlorambucil in patients with CLL and coexisting conditions. N Engl J Med. 2014;370: 1101-1110.

32. Goede V, Fischer K, Engelke A, et al. Obinutuzumab as frontline treatment of chronic lymphocytic leukemia: updated results of CLL11 study. Leukemia. 2015;29(7):1602-1604.

33. Goede V, Engelke A, Fischer K, et al. Salvage therapy with obinutuzumab (GA101) plus chlorambucil (Clb) after treatment failure of Clb alone in patients with chronic lymphocytic leukemia and comorbidities: results of CLL11 study. [abstract no 3327]. In: 56th American Society of Hematology Annual Meeting and Exposition, San Francisco; 2014.

34. Freeman CL, Morschhauser F, Sehn LH, et al. Pattern of cytokine release in patients with chronic lymphocytic leukemia treated with obinutuzumab and possible relationship with development of infusion related reactions (IRR). Blood. 2014;124(21):4674.

35. Sachdeva M, Dhingra S. Obinutuzumab: a FDA approved monoclonal antibody in the treatment of untreated chronic lymphocytic leukemia. Int J Appl Basic Med Res. 2015;5(1):54-57.

36. Perrillo R, Martin P, Lok A. Preventing hepatitis B reactivation due to immunosuppressive drug treatments. JAMA. 2015;313(16): 1617-1618

37. Redbook [online database]. Available from: http://www.redbook.com/ redbook/online. Accessed June 20, 2014.

38. Kharfan-Dabaja MA, Wierda WG, Cooper LJN. Immunotherapy for chronic lymphocytic leukemia in the era of BTK inhibitors. Leukemia. 2014;25:507-517.
39. Hillmen P, Skotnicki AB, Robak T, et al. Alemtuzuamb compared with chlorambucil as first-line therapy for chronic lymphocytic leukemia. J Clinc Oncol. 2007;25(35):5616-5623.

40. Stilgenbauer S, Dohner H. Campath-1H-induced complete remission of chronic lymphocytic leukemia despite p53 gene mutation and resistance to chemotherapy. $N$ Engl J Med. 2002;347:452-453.

41. Lozanski G, Heerema NA, Flinn IW, et al. Alemtuzumab is an effective therapy for chronic lymphocytic leukemia with p53 mutations and deletions. Blood. 2004;103:3278-3281.

42. Hillmen P, Robak T, Janssens A, et al. Chlorambucil plus ofatumumab versus chlorambucil alone in previously untreated patients with chronic lymphocytic leukemia (COMPLEMENT 1): a randomized, multicentre, open-label phase 3 trial. Lancet. 2015;385:1873-1883.

43. Ladyzynski P, Molik M, Foltynski P. A network meta-analysis of progression free survival and overall survival in first-line treatment of chronic lymphocytic leukemia. Cancer Treat Rev. 2015;41(2): 77-93.

44. Reyes C, Gazauskas G, Becker U, et al. Cost-effectiveness analysis of obinutuzumab versus ofatumumab for previously untreated chronic lymphocytic leukemia (CLL) [abstract no 1324]. In: 56th American Society of Hematology Annual Meeting and Exposition, San Francisco; 2014.

45. Motta G, Cea M, Moran E, et al. Monoclonal antibodies for non-Hodgkin's lymphoma: state of the art and perspectives. Clin Dev Immunol. 2010;Article ID 428253:doi:10.1155/2010/428253.

46. Shah A. Obinutuzumab: a novel anti-CD20 monoclonal antibody for previously untreated chronic lymphocytic leukemia. Ann Pharmacother. 2014;48(10):1356-1361.
Therapeutics and Clinical Risk Management

\section{Publish your work in this journal}

Therapeutics and Clinical Risk Management is an international, peerreviewed journal of clinical therapeutics and risk management, focusing on concise rapid reporting of clinical studies in all therapeutic areas outcomes, safety, and programs for the effective, safe, and sustained use of medicines. This journal is indexed on PubMed Central, CAS,

\section{Dovepress}

EMBase, Scopus and the Elsevier Bibliographic databases. The manuscript management system is completely online and includes a very quick and fair peer-review system, which is all easy to use. Visit http://www.dovepress.com/testimonials.php to read real quotes from published authors. 